\title{
Demographics of alpine skiing and snowboarding injury: lessons for prevention programs
}

\author{
Andrew J Macnab, Robert Cadman
}

\begin{abstract}
Objective-To establish the demographics of ski injury in relation to age, gender, and perceived cause during a representative season to identify potential injury prevention strategies.
\end{abstract}

Setting-Blackcomb Mountain, a world class ski resort in British Columbia, Canada.

Methods-Data were collected from the lift ticket records and from ski patrol injury reports for one season, November to May 1991-2.

Results-There were 720066 skier and snowboarder day visits counted by the mountain's lift ticket records, with a total of 2092 injury reports (incidence 2.91 per 1000 day visits). Of those with significant injuries (those requiring physician care), $1210(58 \%)$ were male. The highest injury rate was among children (age 7-12) and teens (age 13-17) with incidences of 3.18 and 3.34 significant injuries per 1000 skier days, respectively. Head and face injuries constituted $17 \%$ and $22 \%$ of injuries, respectively in these groups. Overall $22 \%$ of head and face injuries were severe enough to cause loss of consciousness or clinical signs of concussion. This was the body region injured most frequently in males. For females over 7 years of age, the knee was the most common site of injury. For youths, the incidence of injuries during school organized activities was $25 \%$ higher than during other outings.

Conclusions-The vulnerability of school group participants suggests special education is warranted. The high incidence of head injuries, particularly among young males, needs to be addressed. In light of the high proportion of this group who already wear helmets, the role of helmets in both protection and possible causation of head injury needs objective research.

(Injury Prevention 1996; 2: 286-289)

British Columbia Children's Hospital, University of British Columbia, Vancouver British Columbia, Canada R Cadman

Correspondence to: Dr AJ Macnab, Intensive Care Unit, BC Children's Care Unit, BC'Children's Vancouver, BC V6H 3V4, Canada.
Keywords: skiing, snowboarding, head injuries, helmet use.

As skiing and snowboarding become more popular, the number of people injured rises and effective injury prevention strategies become increasingly necessary. Some injuries from these winter sports are severe, resulting in spinal cord injuries, significant head trauma, and even death. To begin the process of developing a scientifically based ski injury prevention program, we conducted a study of all injuries reported to the ski patrol during one complete ski season at Blackcomb Mountain, Canada. Blackcomb is a large resort that attracts skiers and snowboarders from all over the world because it has the greatest vertical rise in North America and has trails for all levels of skier.

\section{Methods}

This study is a descriptive analysis of injuries reported to the ski patrol over a single complete winter ski season (22 November 1991 to 24 May 1992). All injury reports (IRs) (for significant injuries requiring referral to a physician for medical care) and minor treatment forms (MTFs) (for incidents requiring only first aid attention) completed by the Blackcomb ski patrol over this period were reviewed. IRs and MTFs were crossed referenced with the ski patrol dispatcher's log to ensure that all had been obtained.

Nine of the fields recorded on these forms were deemed to be factors that might affect the type or incidence of injuries. The variables that were tabulated are: age, gender, skier ability (self report), equipment status (owned, rented, borrowed), snow conditions, weather conditions, time of day, self reported cause of incident, and description of injury.

Age specific lift ticket sales data were collected. Because of the introduction of computerized methods of documenting skier admission to the mountain, these data were available and provide an accurate denominator: all multiuse tickets and season's passes are bar coded and computer scanned at the time of use; unused tickets and foot passengers were excluded; and two half day tickets were combined to give one skier visit to decrease the effect of shorter days being skied by young or older groups. Age groups identified by ticket sales were: tot ( $0-6$ years), child ( $7-12$ years), youth (13-17 years), adult (18-64 years), and young at heart $(65+$ years $)$.

Data analysis was conducted using Systat $5.2^{1}$ and QuattroPro $6.0 ; \chi^{2}$ tests were conducted where appropriate.

Results

During the 1991-2 ski season, there were 720066 skier and snowboarder day visits based on the mountain's lift ticket records. (Foot passengers were excluded and two half day passes were counted as a single day visit.) A total of 1530 IRs and 562 MTFs were completed by the ski patrol. The total injury rate 
was 2.91 incidents per 1000 day visits (IRs plus MTFs), and the significant injury rate was $2 \cdot 12$ per 1000 day visits (IRs only). Because there are no lift ticket data on gender, we were unable to determine injury incidence rates by gender, although males sustained $58 \%$ of the 2092 injuries.

One hundred and fifty six of all injuries reported involved snowboarders (87 reports failed to specify whether snowboarding or skiing was involved). Although no data could be collected on numbers of skiers compared with snowboarders, we estimated that $5 \%$ were snowboarders in the 1991-2 season. This is based on previous reports of $1-2 \%$ of users being snowboarders before $1990,{ }^{2}$ and present estimates by the Blackcomb ski patrol of $15 \%$. Thus, the percentage of all injuries that involved snowboarders, approximately $7.5 \%$, is higher than expected.

Table 1 summarizes the lift ticket, IR, and MTF data. Children (age 7-12) and teens (age $13-17)$ were at the greatest risk of injury (3.18 and 3.34 significant injuries per 1000 skier days). Children and teens suffered a disproportionate number of injuries: they constitute $20 \%$ of the skiers/snowboarders over the period studied, but suffered $29 \%$ of the injuries $\left(\chi^{2}=115, \mathrm{df}=1, \mathrm{p}<0.001\right)$.

The most frequently injured body regions were the head or face $(26.5 \%$ of all injuries in males), and the knee (30\% of all injuries in females). The figure presents the percentage of injuries to a particular body region by age and gender. Head and face injuries, and shoulder injuries, were more common among males $\left(\chi^{2}=22, \mathrm{df}=1, \mathrm{p}<0.001\right.$ for head and face injuries), whereas knee injuries were significantly more common among females $\left(\chi^{2}=27, \mathrm{df}=1, \mathrm{p}<0.001\right)$. Table 2 shows the nature of head and face injuries. Twenty two per cent were severe enough to cause loss of consciousness or clinical signs of concussion.

Personal error was the most frequently self reported cause of injury/incident $(57 \%)$ (table 3 ). The second most common cause among those $0-6$ was collision with an object $(17 \%)$, and among those $13-17$ was jumping $(12 \%)$. Those $7-12$ years cited change in snow conditions, collisions with objects, jumping, and human collisions equally frequently $(8 \%)$.

The injury incidence among children/teens participating in school sponsored activities was $5 \cdot 4 / 1000$ day visits, compared with the rate of $4 \cdot 3 / 1000$ day visits among children/teens skiing independently. There were no statistically

Table 1 Total significant injuries ${ }^{\star}$ at Blackcomb Mountain, 1991-2

\begin{tabular}{lcclcl}
\hline $\begin{array}{l}\text { Age } \\
\text { years) }\end{array}$ & $\begin{array}{l}\text { Population } \\
\text { (of total) }\end{array}$ & $\begin{array}{l}\text { Total } \\
\text { injuries }\end{array}$ & $\begin{array}{l}\text { Total injuries/ } \\
\text { 1000 day visits }\end{array}$ & $\begin{array}{l}\text { Significant } \\
\text { injuries }\end{array}$ & $\begin{array}{l}\text { Significant injuries/ } \\
1000 \text { day visits }\end{array}$ \\
\hline $0-6$ & $9182(1)$ & 35 & $3 \cdot 81$ & 16 & $1 \cdot 74$ \\
$7-12$ & $46487(6)$ & 221 & $4 \cdot 75$ & 148 & $3 \cdot 18$ \\
$13-17$ & $86429(12)$ & 376 & $4 \cdot 35$ & 289 & $3 \cdot 34$ \\
$18-64$ & $569423(79)$ & 1441 & 253 & 1062 & $1 \cdot 87$ \\
$65+$ & $8545(1)$ & 19 & $2 \cdot 22$ & 15 & $1 \cdot 75$ \\
Total & $720066(100)$ & 2092 & 2.91 & 1530 & $2 \cdot 12$
\end{tabular}

*Total injuries include MTFs (that is, first aid on the mountain) and IRs (that is, those requiring physician care). Significant injuries include only IRs. significant effects on injury incidence related to skier ability, equipment status, snow conditions, weather conditions, or time of day.

\section{Discussion}

The total rates of injury found in this study are consistent with those previously reported. ${ }^{34}$ As with other studies, some injuries will have been missed if the ski patrol was not involved. Minor injuries may be treated by family members, and more serious injuries may not be recognized until the skier is off the mountain. The high incidence of injury found in children and teens in this study is of concern. It suggests that these groups are at particular risk and could benefit most from an effective injury prevention program, particularly before school sponsored events.

The head/face, knee, and shoulder were the most frequent sites of injury. This pattern is consistent with reports by others, ${ }^{4-11}$ whereas
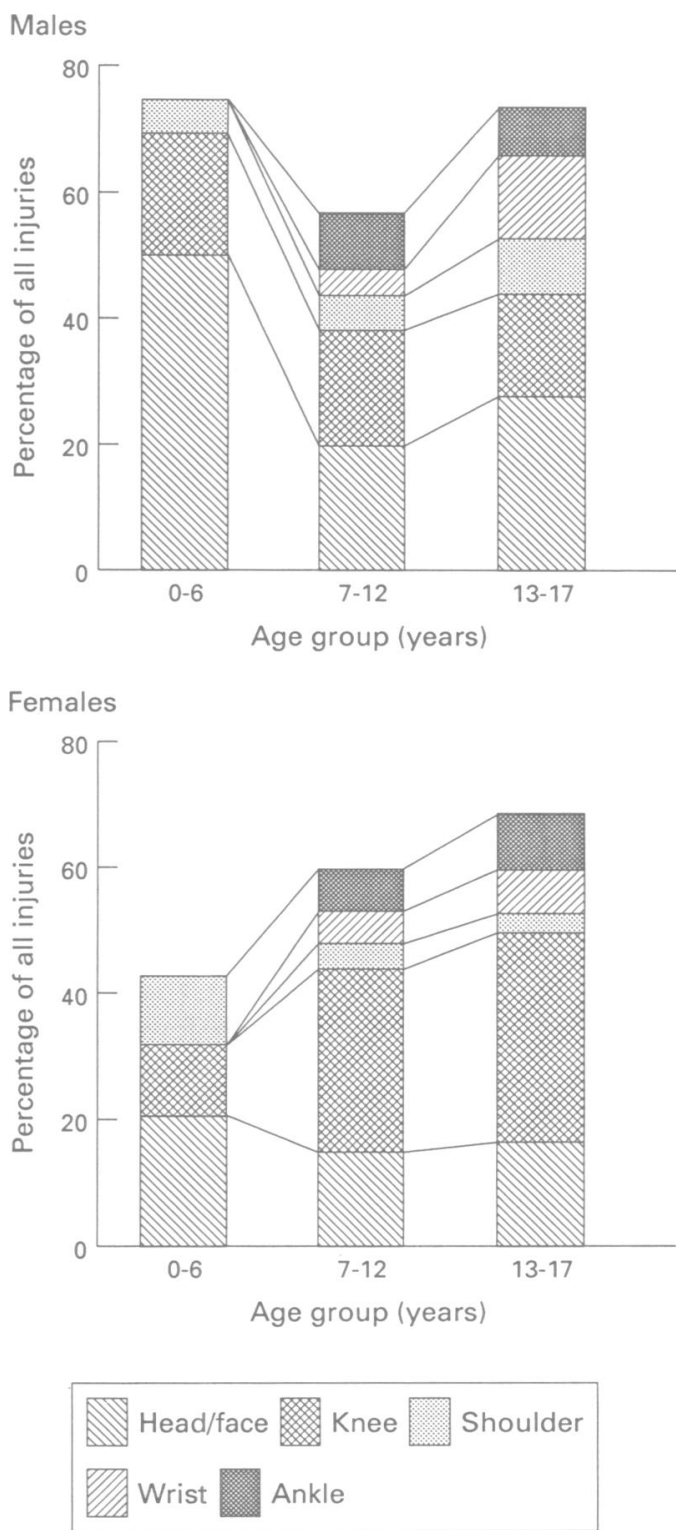

Site of injury as a percentage of total injuries by age group in males and females. 
Table 2 Nature of head and face injuries among those $0-17$ years

\begin{tabular}{lcc}
\hline Injury & $\begin{array}{l}\text { No of } \\
\text { injuries }\end{array}$ & $\begin{array}{l}{ }_{0}^{\circ} \text { Of head and } \\
\text { face injuries }\end{array}$ \\
\hline Laceration & 48 & $43 \cdot 2$ \\
Contusion & 28 & $25 \cdot 2$ \\
Concussion & 19 & $17 \cdot 1$ \\
Unconsciousness & 5 & $4 \cdot 5$ \\
Eye injury & 4 & $3 \cdot 6$ \\
Laceration and contusion & 3 & $2 \cdot 7$ \\
Combative patient & 2 & $1 \cdot 8$ \\
Epileptic seizure & 1 & $0 \cdot 9$ \\
Headache & 1 & $0 \cdot 9$ \\
\hline
\end{tabular}

Table 3 Age specific self reported cause of injury $\left({ }^{\circ}\right.$ of those injured)

\begin{tabular}{lllccl}
\hline $\begin{array}{l}\text { Age } \\
\text { years) }\end{array}$ & $\begin{array}{l}\text { Personal } \\
\text { error }\end{array}$ & $\begin{array}{l}\text { Change in } \\
\text { snow conditions }\end{array}$ & $\begin{array}{l}\text { Object } \\
\text { collision }\end{array}$ & fumping & $\begin{array}{l}\text { Human } \\
\text { collision }\end{array}$ \\
\hline $0-6$ & 43 & 0 & 17 & 9 & 9 \\
$7-12$ & 57 & 8 & 7 & 8 & 8 \\
$13-17$ & 59 & 9 & 6 & 12 & 2 \\
All & 60 & 8 & 7 & 7 & 5 \\
\hline
\end{tabular}

the rates of ankle and wrist injuries in the 7-12 and 13-17 age groups may be related to increased snowboarding in these groups. ${ }^{21112}$

In view of the incidence of significant head and face injury in this study and our observations that a large percentage of children were wearing helmets when injured, helmets should be investigated to determine whether those currently in use are effective. ${ }^{1314}$ It is possible that helmet use contributes to situations that result in injury, perhaps by interfering with balance, peripheral vision, or hearing. A questionnaire that surveyed helmet use among those injured in the 1992-3 ski season indicated that in the $0-6,7-12$, and $13-17$ age groups, helmets were never worn by $20 \%, 55 \%$, and $92 \%$, respectively.

The majority of skiers reported that the cause of their injury was personal error (loss of control, for example crossing ski tips or falling for no apparent reason). Jumping, impact with natural or man made objects, skier collisions, falls resulting from changing snow conditions, skiing off the trail, and falling during terrain transition are other self reported causes. Collision with another person constitutes only $4.8 \%$ of injuries $(0 \cdot 14$ incidents per 1000 day visits). Injuries involving lifts are few on Blackcomb: fewer than $5 \%$ of injuries involve the lift line, loading, riding, or unloading from the lift.

\section{PREVENTION PROGRAMS}

Developing injury prevention programs for skiers and snowboarders requires careful analysis of the population at risk and the determinants of behaviour. The possible approaches involve a hierarchy of interventions, ranging from education or behaviour modification techniques, through improved technology (changes in equipment), to enactment of legislation. Methods for planning, implementing, and evaluating prevention programs have been described by others. ${ }^{15-17}$ Our study suggests that, because of the range of
Our study suggests that, because of the range of factors involved, a single prevention program is unlikely to achieve the goal of a major reduction in serious injury.

Many young people enjoy skiing at the edge of their ability to maintain control. However, children (aged 11-16) 'are usually of sufficient skill to ski rapidly, yet all too often show poor judgment and recklessness which all too frequently results in injury'. ${ }^{5}$ The public's perception that injuries are often the result of human collisions is not substantiated in this study. Greater safety awareness and psychomotor skill development, including jump planning, might reduce the incidence of injury in this group.

The proportion of females injuring their knees is two to five times that of males in all age groups above 7 years. This suggests the need for gender specific equipment and/or training. Males are more prone to injure their heads or shoulders than are females. If this knowledge is disseminated, there is the opportunity for those at risk to use appropriate knee braces or helmets.

Although the generalities of helmet use have been discussed previously, ${ }^{18}$ no studies have reported on their efficacy in young skiers. A depressed skull fracture has been described in a child wearing a helmet. ${ }^{14}$ What dictates who wears helmets? Is role modelling by professional ski racers helpful? Does current helmet design compromise a child's ability to hear? Must a jaw guard be used? Are the helmets used at present, that is hard shell helmets designed to withstand impact with a solid object, appropriate for the impact with soft snow? Studies are needed to quantify the injury rates in helmet users and non-users and to address these questions. Design of helmets could be improved to allow less disturbance of hearing and vision, and the composition of the materials used could be selected to deal with impacts with snow or rigid objects such as trees.

Physicians have a role in the prevention of sports injury. Opportunities to educate, or influence behaviour, generally occur either after minor injury or at routine office visits. Physicians can inquire about fitness, knowledge of safety rules, and use of appropriate equipment; they can encourage proper instruction, equipment safety checks, and informed risk taking behaviour. The latter is achieved through provision of information on the incidence, frequency, and severity of ski injuries based on studies such as that reported here.

Injury prevention strategies to reduce the incidence of alpine skiing and snowboarding injuries will need to be multifactorial. Ski resorts can police for dangerous behaviours and actively reinforce desired behaviour. For example, good behaviours could be rewarded with small tokens (for example free soft drink coupons), and a second coupon could be issued simultaneously to be passed to a friend who must complete a skill testing question (for example fill in the skier safety code) before receiving the reward.

Although the demographics of injury des- 
cribed in skiers and snowboards are specific to British Columbia, we believe they have relevance for most ski facilities. The issue of defining appropriate injury prevention strategies for this population is relevant world wide.

The authors are grateful for the assistance given with the logistics of this study by Blackcomb Mountain and acknowledge the financial support for aspects of this research provided by Safe Start, the injury prevention programme at BC Children's Hospital funded by the Royal Bank.

1 Wilkinson L, Hill M, Vang E. Systat 5·2. Illinois: Systat Inc, 1992.

2 Abu-Laban RB. Snowboarding injuries: an analysis and comparison with alpine skiing injuries. Can Med Assoc $\mathcal{F}$ 1991; 145: 1097-103.

3 Dolinar J. Keeping ski injuries on the down slope. Physician Sportsmed 1991; 19: 120-3.

4 Johnson R, Bahniuk E, Ettlinger C, Mote C, Shealy J. A round table: downhill skiing injuries. Physician Sportsmed 1987; 15: 107-14.

5 Blitzer C, Johnson R, Ettlinger C, Aggeborn K. Downhill skiing injuries in children. Am $\mathcal{F}$ Sports Med 1984; 12: 142-7.

6 Ekeland A, Holtmoen A, Lystad H. Alpine skiing injuries in Scandinavian skiers. In: Mote Jr CD, Johnson RJ, eds. Skiing trauma and safety: eighth international symposium. Philadelphia: American Society for Testing and Materials, 1991: 144-51.

7 Engkvist $O$, Ungerholm S, Gierup J. Skiing injuries in children and adults: trends during an eight year period. skiing trauma and safety: fifth international symposium.
Philadelphia: American Society for Testing and Materials, 1983.

8 Laskowski ER, Murtaugh PA. Snow skiing injuries in physically disabled skiers. Am $\mathcal{F}$ Sports Med 1992; 20: 553-7.

9 Matter P, Ziegler WJ, Holzach P. Skiing accidents in the past 15 years. F Sports Sci 1987; 5: 319-26.

10 Oliver B, Allman F. Alpine skiing injuries - an epidemiological study. In: Mote Jr CD, Johnson RJ, eds. Skiing trauma and safety: eighth international symposium. Philadelphia: American Society for Testing and Materials, 1991: 164-9. 11 Pino EC, Colville MR. Snowboarding injuries. Am 7 Sports

12 Gagnon R, Heneveld E, Beranek S, Fry P. Snowboarding injuries. Physician Sportsmed 1992; 20: 114-22.

13 Lindsjo $U$, Hellquist E, Engkvist O, Balkfors B. Head injuries in alpine skiing. In: Mote Jr CD, Johnson RJ, eds. injuries in alpine sking. In: Mote $\mathrm{r} \mathrm{CD}$, Johnson $\mathrm{RJ}$, eds.
Skiing trauma and safety: fifth international symposium. Philadelphia: American Society for Testing and Philadelphia: American

14 Myles ST, Mohtadi NGH, Schnittker J. Injuries to the nervous system and spine in downhill skiing. Can $\mathcal{F}$ Surg 1992; 35: 643-8.

15 Bouter L, Kok G. Planning health education for downhill skiers. In: Mote Jr CD, Johnson RJ, eds. Skiing trauma and safety: eighth international symposium. Philadelphia: American Society for Testing and Materials, 1991: $249-56$.

16 Damoiseaux V, de Jongh A, Bouter L, Jan Hosper $H$. Designing effective health education for downhill skiers: results of a randomized intervention study. In: Mote Jr, CD, Johnson RJ, eds. Skiing trauma and safety: eighth international symposium. Philadelphia: American Society for Testing and Materials, 1991: 241-8.

17 Kok G, Bouter L. On the importance of planned health education; prevention of ski injury as an example. $A m \mathcal{F}$ Sports Med 1990; 18: 600-5.

18 Sherry E, Korbel P, Henderson A. Children's skiing injuries in Australia. Med $\mathcal{F}$ Aust 1987; 147: 193-5.

\section{Childproofing the world}

A perfectly serious essay begins, 'Our buckle-up, just-say-no society has evolved into a litigious, crybaby, blame-somebody-else world in which even cigarette lighters must be safe around unsupervised 6 year olds'. The writer insists that as a result of this attitude 'every disposable lighter on the market is damn near useless' because 'it protests as vociferously when a man of 40 attempts to use it as it does with a child of 2'. He fears an inevitable chain will follow, including 'childproof cigarettes, childproof cars, and ... childproof heavy objects'. Anderson also complains about 'being constantly nagged to buckle-up, slow down' ... and blames Moms - an overwhelming matriarchy - for all these horrible happenings (CE Anderson, Globe and Mail, 13 December 1995).

\section{'Cocooning our children'}

A like minded article, prompted by a drowning, near drowning, and asphyxiation, asks if we are not becoming over protective? Fortunately, the question is a rhetorical one, and the article more balanced than its title (above) suggests. It highlights the link between poverty and high injury rates and indicates that one mechanism behind this may be the high cost of safety equipment. Strangely, it quotes an expert on families who adds, 'We have managed to make parents so safety conscious we take the joy out of parenting'. (Editor's note: perhaps, but not nearly so joyless as the feelings of parents whose child has died of a preventable injury ...) (C Lawson, Ottawa Citizen, 19 June 1996).

\section{Traffic lights in Miami}

In a strange echo from the past, Dave Barry writes: 'I got to thinking about courtesy the other day when a woman hit me with her car'. He goes on to admit it was his fault because he was crossing on a pedestrian crosswalk, saw the car approaching, and 'like a total idiot, assumed he would stop' because there was a sign facing her, saying 'STOP'. He explains that in Miami it is not customary to stop for stop signs because if you do other motorists will assume you are a tourist and therefore unarmed, and will help themselves to your money and medically valuable organs. Barry adds, 'This is what a traffic light means to a Miami driver: green: proceed, yellow: proceed much faster, red: proceed while gesturing'. (Editor's note: Barry is humorist, but this is less funny than he intended because it comes too close to the truth for many of us - not just those in Miami.) (Australian Financial Review, 7 June 1996) (IS). 